\title{
Design Proposal of a Prototype for Sawdust Pellet Manufacturing through Simulation
}

\author{
J. C. Paredes-Rojas $\mathbb{D}^{1,2}$ C. R. Torres San Miguel ${ }^{1},{ }^{3}$ A. I. Flores Vela, ${ }^{1,2}$ B. Bravo-Díaz, ${ }^{1,2}$ \\ C. De la Cruz Alejo, ${ }^{2}$ and D. Palma Ramírez ${ }^{1}{ }^{1}$ \\ ${ }^{1}$ Instituto Politécnico Nacional, Centro Mexicano para la Producción Más Limpia (CMPL), Av. Acueducto S/N, \\ La Laguna Ticomán, 07340 Mexico City, Mexico \\ ${ }^{2}$ Instituto Politécnico Nacional, \\ Laboratorio Nacional de Desarrollo y Aseguramiento de la Calidad en Biocombustibles (LANDACBIO), \\ Centro Mexicano para la Producción más Limpia, Av. Acueducto de Guadalupe S/N, La Laguna Ticomán, \\ 07340 Ciudad de México, Mexico \\ ${ }^{3}$ Instituto Politécnico Nacional, Escuela Superior de Ingeniería Mecánica y Eléctrica, \\ Sección de Estudios de Posgrado e Investigación, Unidad Profesional "Adolfo López Mateos", Edificio 5 Tercer Piso, \\ Del. Gustavo A. Madero, Col. Lindavista, 07738 Mexico City,, Mexico
}

Correspondence should be addressed to J. C. Paredes-Rojas; paredesrojasjc@gmail.com

Received 6 September 2019; Accepted 6 January 2020; Published 12 March 2020

Guest Editor: Costica Bejinariu

Copyright $\odot 2020$ J. C. Paredes-Rojas et al. This is an open access article distributed under the Creative Commons Attribution License, which permits unrestricted use, distribution, and reproduction in any medium, provided the original work is properly cited.

\begin{abstract}
Mexican industry generates tons of organic wastes that are not used and cause social, environmental, and health problems. The main organic residue which is generated during wood production is the sawdust (biomass). In order to reduce the problems generated by its waste, a prototype to manufacture biofuel pellets was designed by considering a flat die pelletizing machine according to the standard EN 14961-2. The machine design consists of stainless steel 304 and carbon steel to produce pellets of $6 \mathrm{~mm}$ and $30 \mathrm{~mm}$ in diameter and length, respectively, at 50-100 rpm. The matrix types proposed were radial, spiral, and hexagonal. In order to be constructed quickly, the design is standardized. Results from finite-element analysis indicate that it is possible to manufacture pellets from 50 to $1000 \mathrm{PSI}(344.7 \mathrm{kPa}$ to $6894.7 \mathrm{kPa})$ with this design complying with the standard.
\end{abstract}

\section{Introduction}

The use of fossil fuels as primary energy source has led to a negative impact on the environment such as the global warming and air pollution. Worldwide efforts are being made to produce different technologies based on environmentally-friendly energy production in the last years $[1,2]$.

Currently, the industry in Mexico has shown interest in substituting fossil fuels by those renewable energy sources [3]. Specifically, the sawmill industry generates a huge amount of waste that complicates the management in parts of the country. Based on this demand, one of the most important alternatives for the development of new products is its biomass [4]. In order to reduce this problem, biofuel pellets from sawdust are a new source of energy, which can be of different types such as briquettes, pales, cubes, wood chips, and pellets [5]. Moreover, beside biofuel, the pellet can be used even for more advance purposes including organic pellet fertilizer production following a composting period and specific procedure $[6,7]$. The process to obtain the pellets consists in the collection of raw material, drying, grinding, conditioning, pelletizing/briquetting, and screening/sieving. For this purpose, two pelletizer types can be found: the flat die roller press and the ring die press [8]. Ring die presses are considered as the optimal technologies for wood-derived pellets [9].

Computer-aided technology offers a favorable route to make use of experimental know-how and guide analysis for novel and efficient technologies that allow a fast, cost-effective, 
and automated evaluation of a great number of characteristics that may lead to highly efficient machinery. Experimentally obtained results to formulate the mathematical representations are used either in computer simulation or optimization in further experiments to verify the results and the optimization [10]. In this manner, computer-aided technologies play a significant role in the field of solid biofuel technologies. Modelling and simulation of the components of a pelletizing machine are necessary to understand conceptually the systems [11].

Mexico is a country with a wide variety of renewable biomass resources, the technologies for these purposes are deficient, and palletizing machine used to produce sawdust biofuel is topics just emerging [12].

This research is focused on the design and analysis of a flat die compaction machine to produce pellets from sawdust biomass. The roller section as well as the flat die were selected to determine the final parameters to create and set up the geometry of the pelletizer. Then, the main aim of this work was to design and compare the radial, spiral, and hexagonal matrixes to simulate a better pellet production through finite-element analysis. The paper is organized as follows. In Section 2, recent studies are reported in this section. Section 3 describes the technical specifications for pellets machine design and pellets characteristics on standard EN 14961-2. Section 4 shows the main components of the pellets machine, sawdust pressed in a heat-cold press machine, pellet dimensions, sawdust compression, displacement, and safety factor. Section 5 presents conclusions and future work.

\section{State of the Art}

A utility model described in CN200945426Y (Chinese) consists of a wood processing equipment, where at least two rotatable rollers oppositely arranged on a driving shaft along the axial direction and a roller ring module peripherally arranged. Similarly, the invention in RU2566692C2 (Russian) describes a press granulator for making particles with modular construction and operation with the aim of being adjusted while avoiding the maintenance of the individual modules. In the U.S. Pat. No. 4,511,321, a machine for densifying and pelleting extrudable material is described. It includes, in combination, a flat horizontal die plate and pressure exerting means overlying the die plate, the pressure exerting means having various alternative forms such as a continuous chain means carrying a plurality of spaced pressure members or a reciprocating frame carrying roller means. The CN205672878U relates to a ring die granulator and a granulating device to provide a simple structure, small volume, high efficiency, and low energy consumption of the ring mold in the machine. Another utility model is a circular die granulator with a vertical main shaft equipped with a double reduction machine which drives the main shaft and rotates (CN205517625U). As it was stated by Celik et al., the research related to the design of an optimum die by means of computer-aided engineering and structural optimization approaches is very limited [13]. For this design, parameters such as the force required for densification, the capacity, plugger pressure surface, diameter and hydraulic cylinder speed, densifier flow rate, hydraulic pump, and motor selection were considered. This machine operates without extrusion, preheating chambers, and ejection problems which were associated with the manual press.

Recently, researchers are using Solidworks ${ }^{\circledR}$ software and FEA tool to simulate machine elements, such as the die [14]. For example, the pressure supported by the hydraulic cylinder in a designed compaction machine is of 100 ton at 10,000 PSI $(100000 \mathrm{~kg}$ at $68947.5 \mathrm{kPa})$, whereby it was necessary to ensure the pressure supported by the rear block, upper block, and compaction matrix as well as the blocker. For this reason, Döring analyzed the maximum tensile, elastic limit, and the security factor of the pieces [15]. On the other hand, Macko group optimized the strength and kinematics of the movement of each component with Solidworks ${ }^{\circledR}$ software in a machine with a capacity of up to $100 \mathrm{~kg} / \mathrm{h}$ [16]. Celik et al. studied the compression ratio (CR) by using a finite-element analysis (FEA) based on design for sample in single-hole flat die parameters (geometry dimensions) against various compression pressure values [13]. Likewise, Šooš et al. developed, designed, and tested a compacting press (with a protected patented) for the production of pressing biofuels of the optimal shape, almost circular shape [17].

In this same context, the fluid mechanics analysis (CFD) of a pellet machine using Solidworks ${ }^{\circledR}$ Flow Simulation indicated that there exist factors important for the granulation. These factors are mainly associated to the quality; some examples are mentioned here: the raw material, performance of the granulating machine and the course of the granulation process, friction in the matrix, surface and material from which the matrix and press are made of, length and diameter of holes in the matrix, the thickness of the biomass material that is subjected to the pressure of the rollers on the surface of the die-the thickness of the material layer reaching the die holes and compression frequency - and the speed at which the press roll moves. However, the model should be limited to one inlet and one outlet and the construction system should be simplified for calculations [18]. In order to analyze a final product in the spheroid shape of pressed biofuels, the construction design of a compacting machine was performed from the optimization of parameters such as the surface to volume ratio, density, and shape. The results indicated that it is necessary to hold the compacted piece for a certain time under high pressure and temperature [19]. Olawale et al. designed a low cost, small scale, 40 bar hydraulic operated piston briquetting machine with a capacity of 120 briquettes per hour [20].

\section{Materials and Methods}

This work begins with the search for information related to the different types of pellets machine reported. Also, data corresponding to the sawdust and the type of steel that would be used were obtained from the compilation of several data sheets and articles in the literature. Subsequently, calculations were realized by determining the parameters related to the roller part and the flat die that must have the vertical bed pelletizing machine to compact the biomass and generate the pellets. A previous test was carried out to evaluate if the biomass from sawdust could be pressed at pressures closed to those of the standards and reported. For this objective, the biomass was 
TABLE 1: Physical and technical characteristics of numerical simulation considering three types of matrixes based on AISI 304 stainless steel.

\begin{tabular}{|c|c|c|c|}
\hline $\begin{array}{l}\text { Matrix type } \\
\text { Study type }\end{array}$ & $\begin{array}{c}\text { Radial } \\
\text { Static analysis }\end{array}$ & $\begin{array}{c}\text { Spiral } \\
\text { Static analysis }\end{array}$ & $\begin{array}{c}\text { Hexagonal } \\
\text { Static analysis }\end{array}$ \\
\hline Avg. element size (fraction of model diameter) & 0.1 & 0.1 & 0.1 \\
\hline Min. element size (fraction of avg. size) & 0.2 & 0.2 & 0.2 \\
\hline Grading factor & 1.5 & 1.5 & 1.5 \\
\hline Density $\left(\mathrm{g} / \mathrm{cm}^{3}\right)$ & 8 & 8 & 8 \\
\hline Mass (kg) & 7. 00588 & 6.70891 & 6.42679 \\
\hline Volume $\left(\mathrm{mm}^{3}\right)$ & 875735 & 838614 & 803348 \\
\hline Yield strength (MPa) & 215 & 215 & 215 \\
\hline Ultimate tensile strength $(\mathrm{MPa})$ & 505 & 505 & 505 \\
\hline Young's modulus (GPa) & 195 & 195 & 195 \\
\hline Poisson's ratio & 0.29 & 0.29 & 0.29 \\
\hline
\end{tabular}

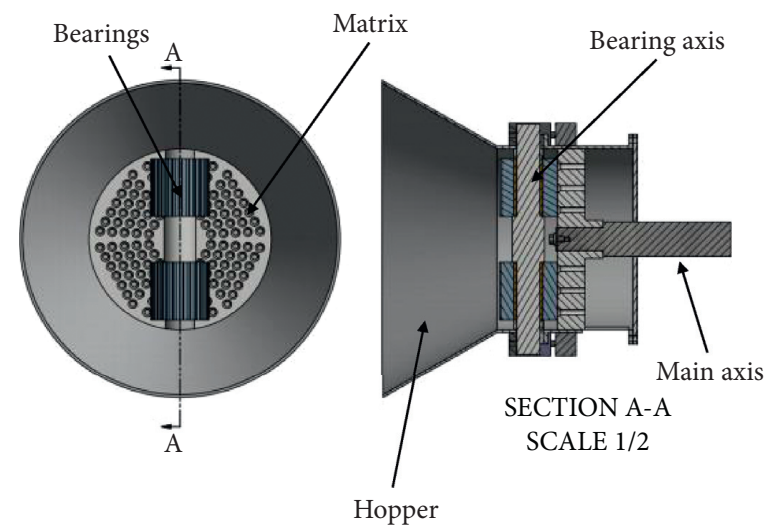

(a)

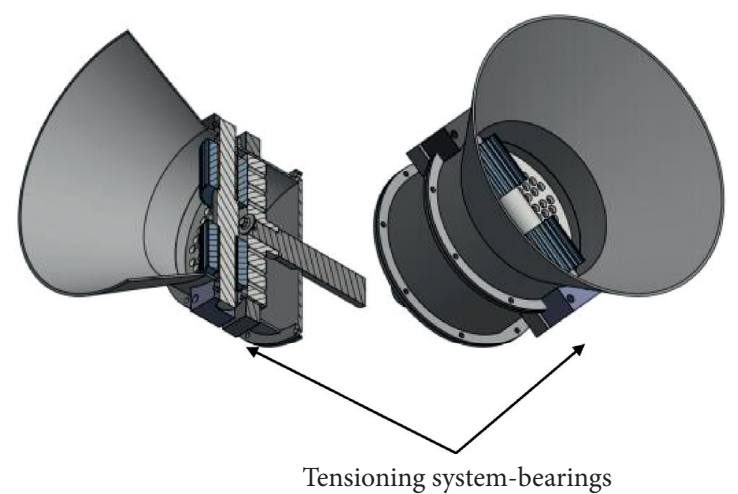

(b)

FIGURE 1: Main components of the pellets machine.

previously dried in an oven at $100^{\circ} \mathrm{C}$ during $24 \mathrm{~h}$; two types of systems based on particle sizes were considered: the first was as received sawdust and the second was the sawdust milled using a sieve of $0.5 \mathrm{~mm}$ in a CT 293 Cyclotec Sample Mill (FOSS, Denmark). A heat-cold press was used to obtain pellets of each particle size. $1 \mathrm{~g}$ of product was then pressed under 50, 100, 500, and $1000 \mathrm{PSI} \quad(344.7 \mathrm{kPa}, \quad 689.4 \mathrm{kPa}, \quad 3447.38 \mathrm{kPa}, \quad$ and $6894.7 \mathrm{kPa}$ ). Once the data were found and established and after calculating the parameters, Solidworks ${ }^{\circledR}$ software was used to create and edit model geometry of the machine. The machine was designed in carbon steel with the exception of the matrix, which is designed with stainless steel 304 for a production from 300 to $1220 \mathrm{~kg} / \mathrm{h}$ of a pellet of $6 \mathrm{~mm}$ and $300 \mathrm{~mm}$ in diameter and length, respectively.

Also, three different matrixes were designed: the radial, spiral, and hexagonal. The radial type is usually used for the pellet production; however, its work surface is not well exploited significantly, whereas designs of the work surface in the spiral and hexagonal types can improve the production of pellets without altering the physical and chemical characteristics of the product. As it is known, the main part is the matrix since it is subjected to stresses and mechanical friction. Thus, the proposed design is needed to be validated by numerical simulation. For this reason, the matrix designs were numerically simulated by using the Software Inventor of Autodesk ${ }^{\circledR}$ version 2017 considering an AISI 304 stainless steel with the physical characteristics seen in Table 1 .
Static analysis with a pressure of $8.89476 \mathrm{MPa}$ and $20 \mathrm{MPa}$ in the work surface of the matrix was evaluated. The first value is the type used for this machine and the optimal observed during the physical test in the heat-cold press to obtain the sawdust pellets; however, it is important to mention that a greater pressure was included to corroborate possible strains.

\section{Results and Discussion}

4.1. Main Components of the Pellet Machine. The modelling obtained from Solidworks ${ }^{\circledR}$ software of the pellets machine is observed in Figure 1, and it is composed by a bearing system of $140 \mathrm{~mm}$ and $80 \mathrm{~mm}$ in length and diameter, respectively. This system has a bearing connector at the ends adjusted by high-pressure screws; it is important to mention that the bearing has an adjusting guide, which regulates the work pressure. It has a production of $60 \mathrm{~kg} / \mathrm{h}$ at 50 to $100 \mathrm{rpm}$ of the disk velocity for a pellet with $6 \mathrm{~mm}$ and $30 \mathrm{~mm}$ in diameter and length, respectively.

4.2. Sawdust Pressed in a Heat-Cold Press Machine. Figure 2 displays the physical aspect of the pellets obtained as primary sawdust and sawdust milled under 50, 100, 500, and 1000 PSI $(344.7,689.4,3447.38$, and $6894.7 \mathrm{kPa}$, respectively).

It is observed that it is possible to obtain pellets from sawdust biomass either as primary or milled at $0.5 \mathrm{~mm}$ of 
50 PSI

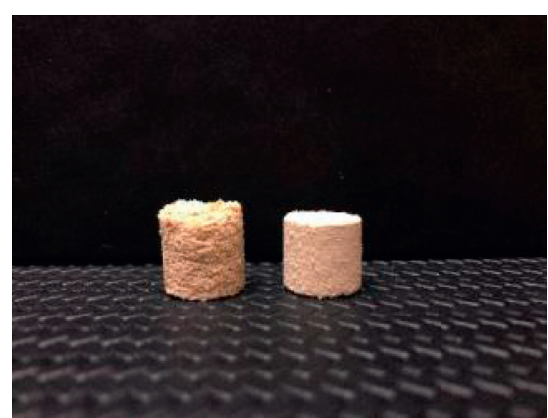

100 PSI

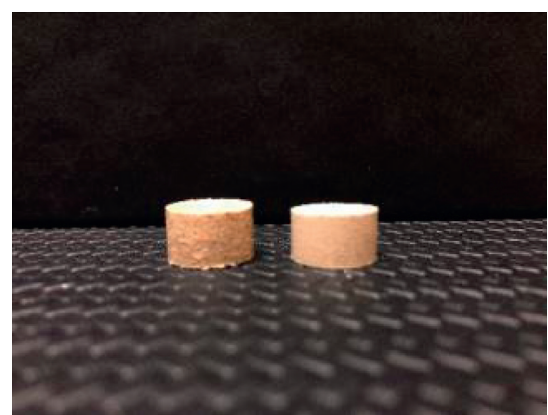

500 PSI

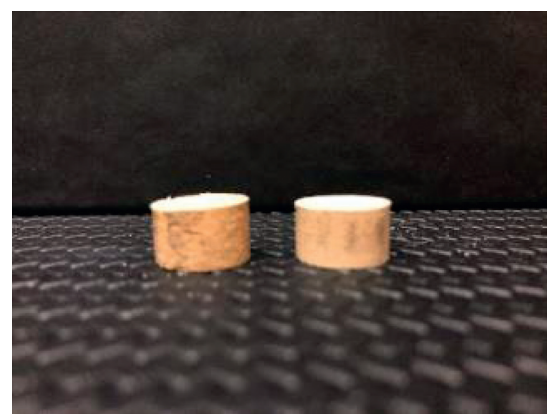

1000 PSI

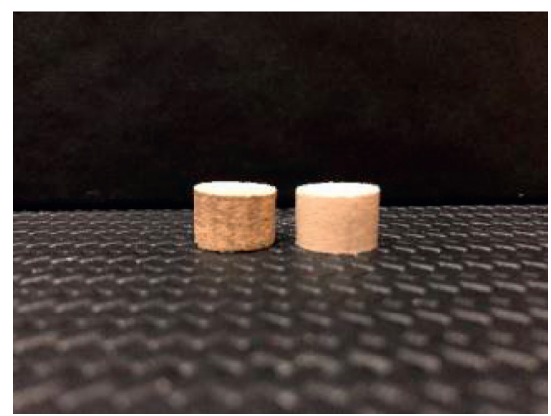

(a)
50 PSI

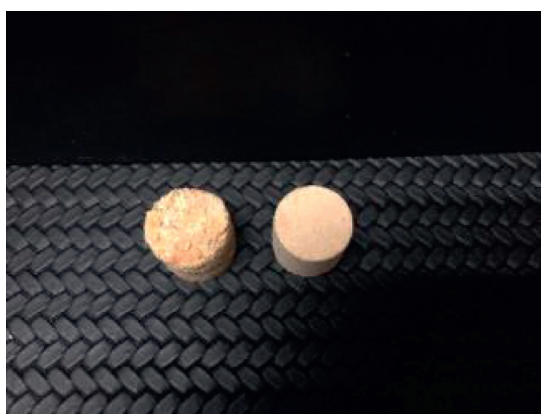

100 PSI

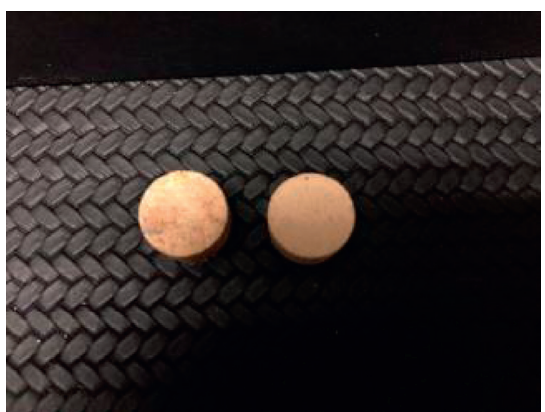

500 PSI

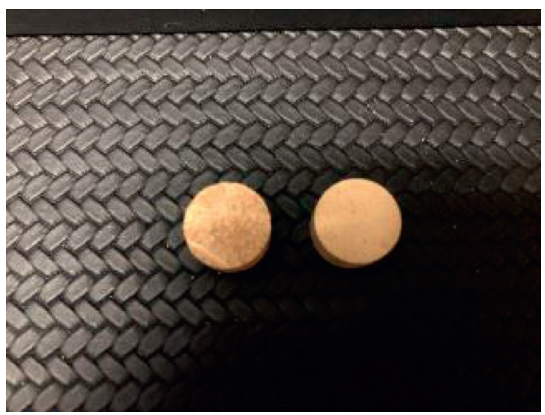

1000 PSI

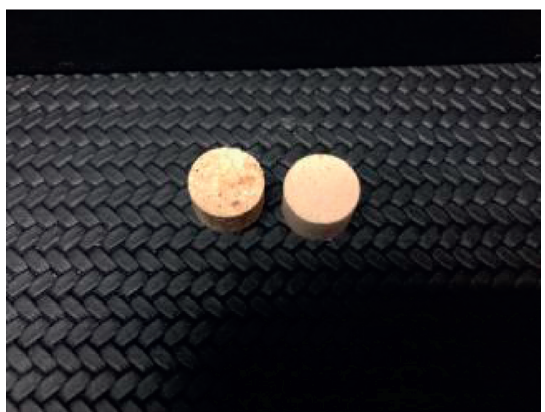

(b)

FIGURE 2: Sawdust pressed under different pressure by using the material as received (a) and milled (b).

particle size. The physical appearance of the pellets improves while increasing the pressure of compacting. For this reason, it was decided and confirmed that 1000 PSI is an optimal condition to use for the machine design.

4.3. Pellet Dimensions. According to the EN-14961-2 and the CEN/TS 14691 standards, a pellet of $6 \mathrm{~mm}$ of diameter $(\varnothing)$ is adequate to avoid the crumbling during transport. For this reason, the pellets studied in this research were selected on the basis of this diameter. The parameters considered for the design of the pelletizing machine are summarized in Table S1 (Supplementary Material). It is important to mention that die pelletizing machine is designed based on the standards EN 14961-2 and CENT/TS 14691, which define the characteristics of the pellet and the certification for solid biofuels, respectively.

4.4. Sawdust Compression. During the compression of sawdust, the rollers have the main function of compressing the 


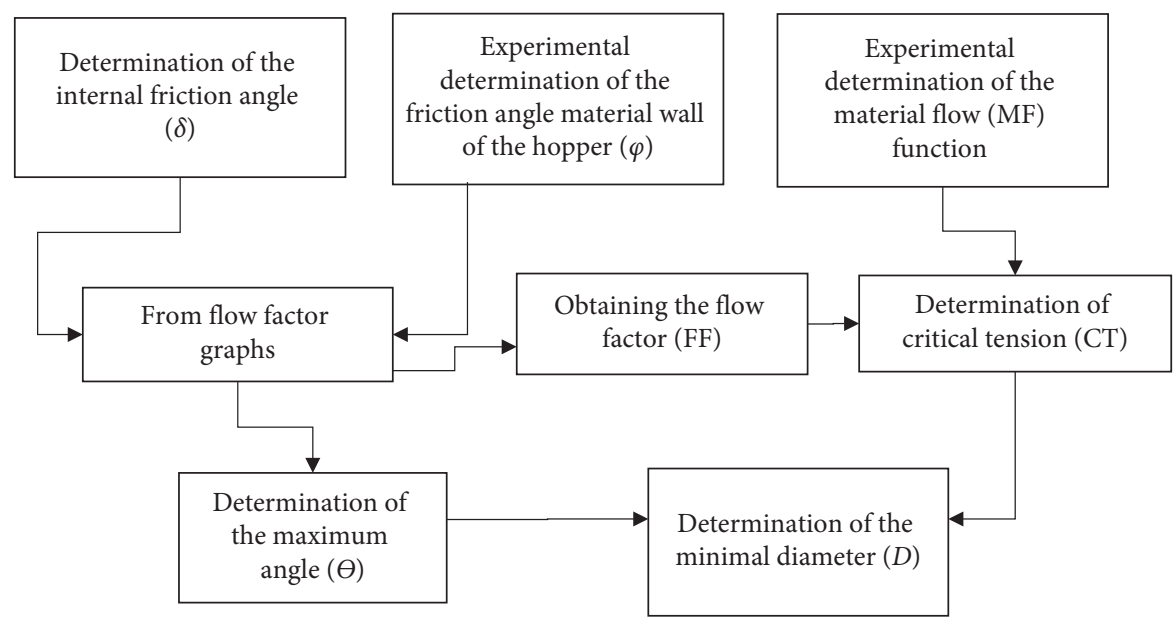

FIGURE 3: Methodology to determine the hopper data for the design.

material in the hole of the circular flat matrix, and as a consequence, forces are generated in the die. For this reason, different parameters need to be in the account for the compression; they are mentioned in Tables S2-S4 (Supplementary Material).

The power of pelletizer is calculated based on the force required by each roller to press the material at the rotation speed of the main matrix. The worm transmissions are generally used for small and medium power that does not exceed $60 \mathrm{~kW}$. In a small space, they can get the ratio of speed relatively high. For this reason, this type of transmission was selected to give movement to the shaft, which is coupled to the rollers. The worm screws are generally of carbon steel ( 0.40 to $0.50 \mathrm{wt}$.\% in C) as well as a low alloy steel with $\mathrm{Cr}$ and $\mathrm{Cr}-\mathrm{Ni}$. The worn of the wheels is manufactured in bronze whose composition depends on the sliding speed and the stress of the transmission (Table S5 Supplementary Material for computation).

The blades are coupled to the main axes, and their rotation speed is of $261 \mathrm{rpm}$. These blades were considered to be located approximately $5^{\circ}$ with respect to the main axis. For the hopper design, the walls with enough steep and low friction were considered. In order to get this goal, the methodology summarized in Figure 3 was used. The results are shown in Table S6 (Supplementary Material for estimation).

For the experimental determination of the material flow (MF) function, the yield stress $\left(Y_{s_{-} c s}\right)$ of the confined sawdust and the main stress $\left(\sigma_{1}\right)$ were considered to construct $\sigma_{1}$ versus $Y_{\mathrm{s}}$ and $\sigma_{1}$ versus $1 / Y_{\mathrm{s}}$ plots (see Table 2 and Figure 4). From these plots, the intercept of both straight lines showed the critical tension (CAS), which in this case was c.a. $2 \mathrm{kPa}$. By using the CAS and (1) and (2), the minimal diameter $\left(D_{\text {minimal }}\right)$ can be found $\left(D_{\text {minimal }}=0.88 \mathrm{~m}\right)$ :

$$
\begin{aligned}
H(\theta) & =2+\frac{\theta}{60^{\circ}}, \\
B & =\frac{H(\theta)(\mathrm{CAS})}{\rho g} .
\end{aligned}
$$

The requirement for this machine is $1 \mathrm{~L}$ in volume, and for this reason, the height $\left(h_{\text {hopper }}\right)$ and the diameter
TABLE 2: Data corresponding to the yield stress of confined sawdust $\left(Y_{\mathrm{s}_{-} \mathrm{cs}}\right)$ and the main stress $\left(\sigma_{1}\right)$.

\begin{tabular}{lc}
\hline$\sigma_{1}(\mathrm{kPa})$ & $Y_{\mathrm{s}}(\mathrm{kPa})$ \\
\hline 5 & 2.23 \\
10 & 3.16 \\
20 & 4.47 \\
44 & 12 \\
100 & 8 \\
140 & 30 \\
\hline
\end{tabular}

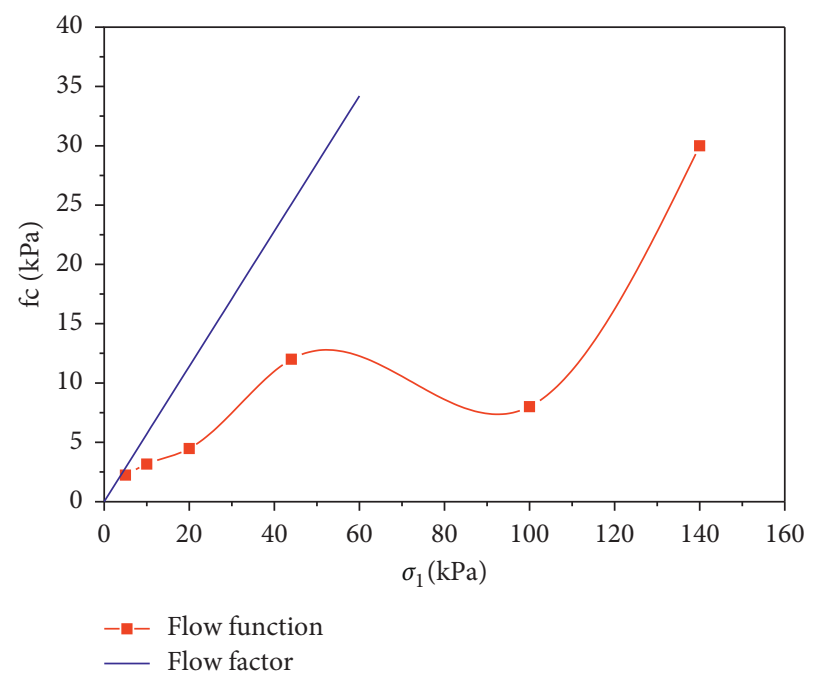

FIGURE 4: Material flow function (MF) and flow factor (FF) graphs.

$\left(D_{\text {hopper }}\right)$ of the hopper were assessed on basis of the following equations:

$$
\begin{aligned}
& V=\frac{\pi}{24 \tan (\theta)}\left(D^{3}-B^{3}\right)+\frac{\pi}{4} D_{\text {hopper }}^{2} h, \\
& 1<\frac{H}{D}<2 .
\end{aligned}
$$

Considering $(h / D)=1$, 


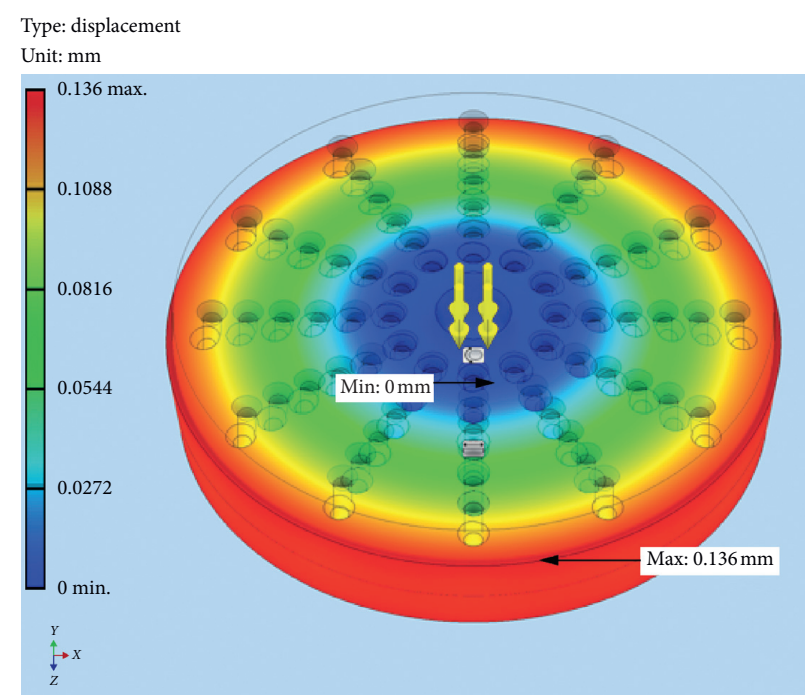

(a)

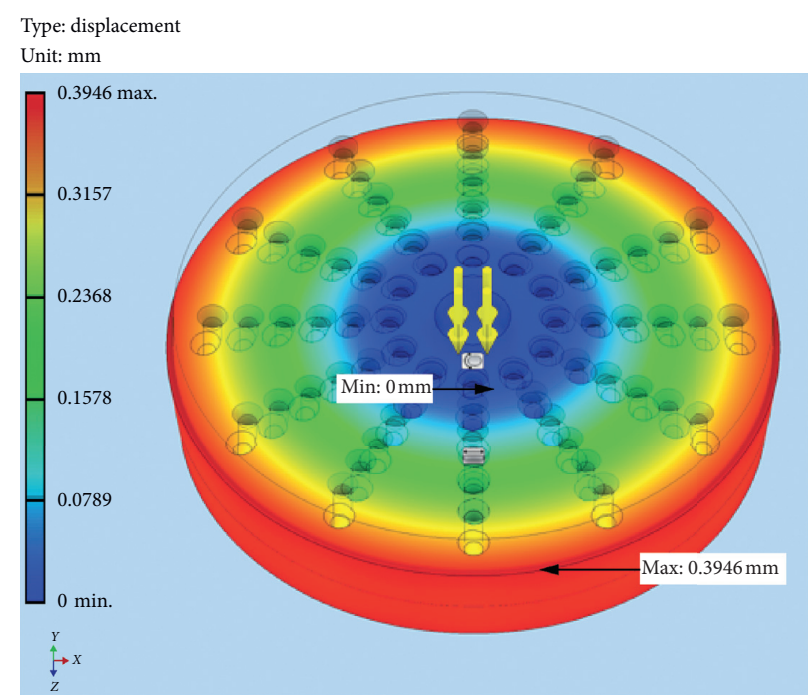

(b)

FIgURE 5: Static analysis of radial matrix at (a) 1000 PSI and (b) 2900 PSI (6894.7 kPa and $19994.8 \mathrm{kPa}$, respectively).

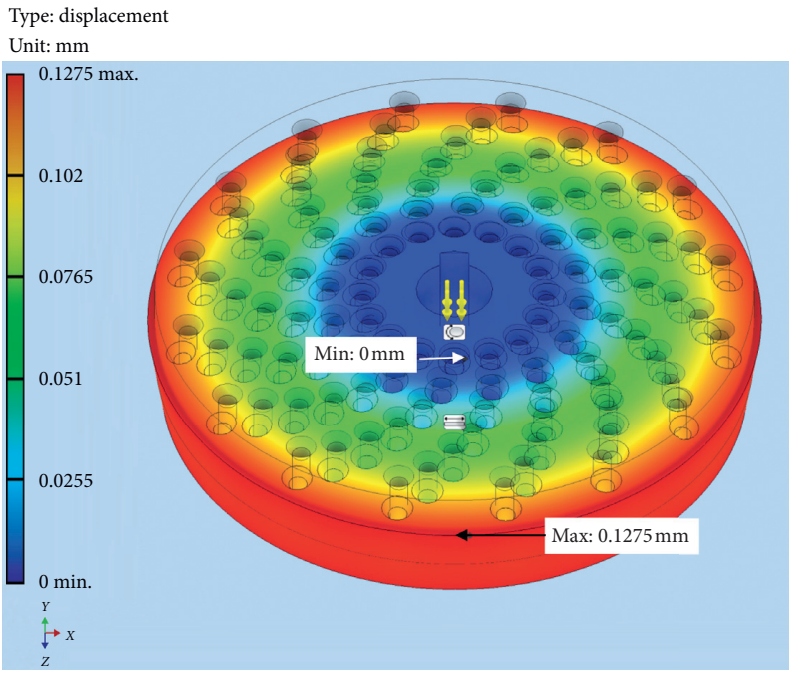

(a)

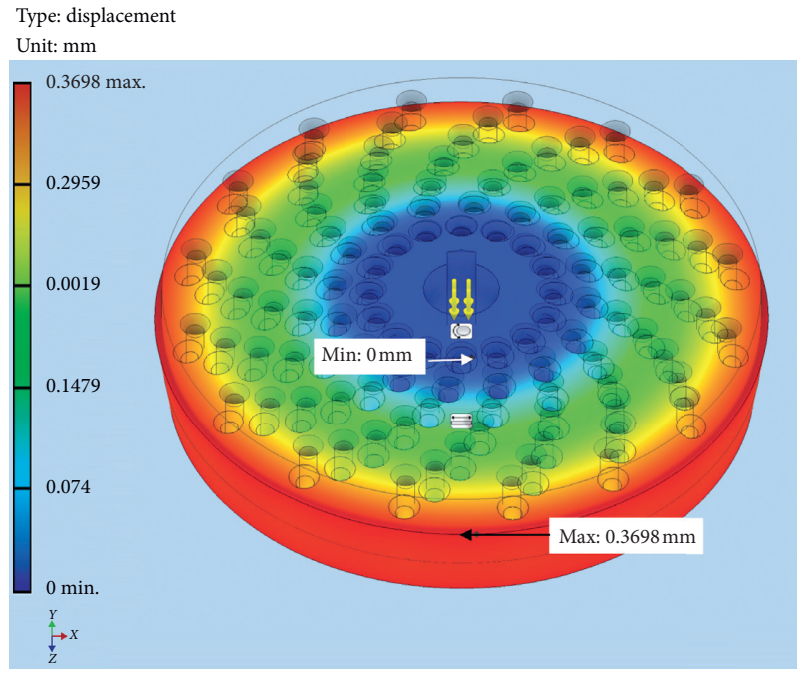

(b)

FIgURe 6: Static analysis of spiral matrix at (a) 1000 PSI and (b) 2900 PSI (6894.7 kPa and $19994.8 \mathrm{kPa}$, respectively).

$$
\begin{aligned}
h_{o} & =\frac{(D / 2)}{\tan \theta}=2.1494 \mathrm{~m}, \\
h_{B} & =\frac{(B / 2)}{\tan \theta}=1.8355, \\
h_{\text {hopper }} & =h_{0}-h_{B} .
\end{aligned}
$$

$D_{\text {hopper }}$ and $h_{\text {hopper }}$ correspond to $1.0305 \mathrm{~m}$ and $0.3139 \mathrm{~m}$, respectively.

4.5. Displacement. The maximum displacements that pressure can generate in the radial matrix were detected at $0.136 \mathrm{~mm}$ and $0.3946 \mathrm{~mm}$ at 1000 PSI and 2900 PSI $(6894.7 \mathrm{kPa}$ and $19994.8 \mathrm{kPa})$, respectively. This can be seen in Figure 5. For spiral matrix, the displacement was $0.1275 \mathrm{~mm}$ and $0.3698 \mathrm{~mm}$ at $1000 \mathrm{PSI}$ and $2900 \mathrm{PSI}$ $(6894.7 \mathrm{kPa}$ and $19994.8 \mathrm{kPa})$, respectively (see Figure 6). And, for the hexagonal matrix, this displacement was $0.1134 \mathrm{~mm}$ and $0.3289 \mathrm{~mm}$ at $1000 \mathrm{PSI}$ and $2900 \mathrm{PSI}$ $(6894.7 \mathrm{kPa}$ and $19994.8 \mathrm{kPa})$, respectively (see Figure 7).

In this sense, the FEA analysis showed that the threematrix designs under a pressure of 1000 PSI and 2900 PSI $(6894.7 \mathrm{kPa}$ and $19994.8 \mathrm{kPa})$ are not affected in their mechanical structure since displacement value for the radial disk is 0.3946 and for the hexagonal disk is 0.3289 under a pressure of 2900 PSI (19994.8 kPa).

The static analysis demonstrates that the geometry is a key factor in the matrix design; the hexagonal matrix generates more pellet production in a ratio of $150 / 72$ than that of the 


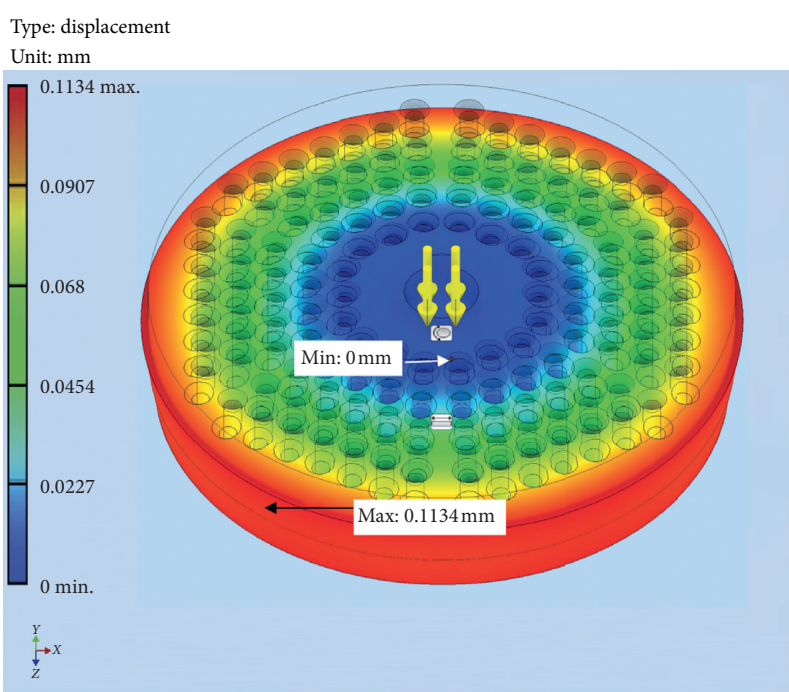

(a)

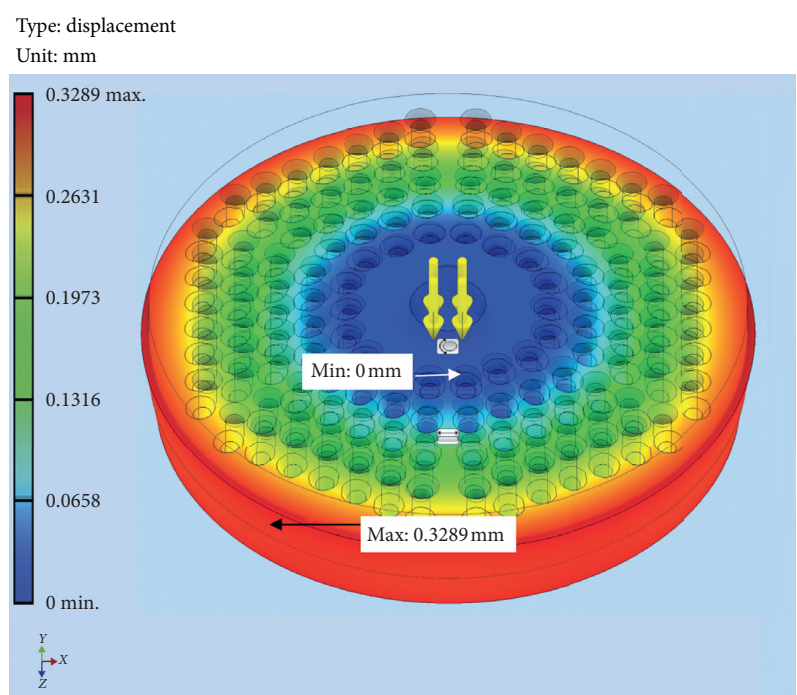

(b)

FIGURE 7: Static analysis of hexagonal matrix at (a) 1000 PSI and (b) 2900 PSI (6894.7 kPa and $19994.8 \mathrm{kPa}$, respectively).

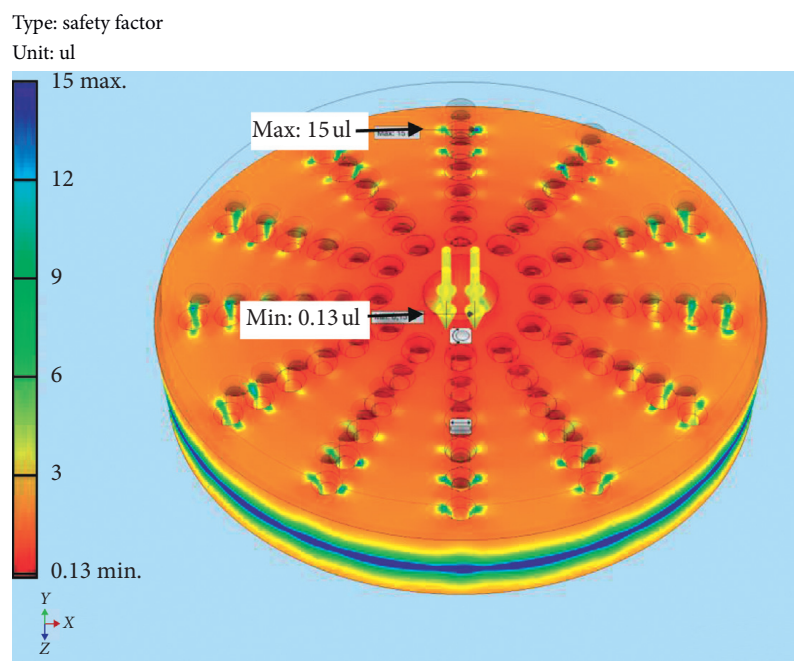

(a)

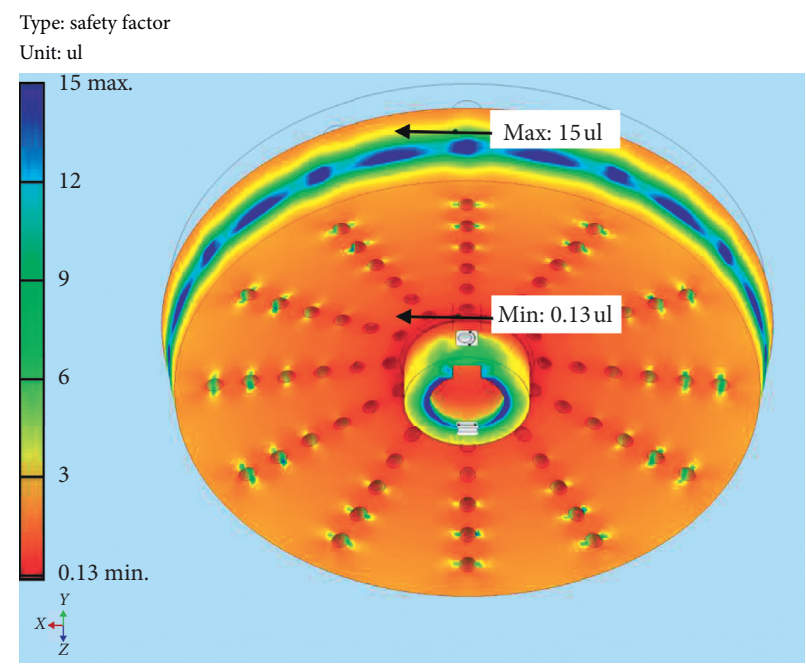

(b)

Figure 8: Safety factor from static analysis of radial matrix at (a) 1000 PSI and (b) 2900 PSI (6894.7 kPa and $19994.8 \mathrm{kPa}$, respectively).

hexagonal and radial; that is, in comparison to the radial matrix, it is possible to double the production with the configuration of the hexagonal matrix, without affecting its structure.

4.6. Safety Factor. The safety factor is the quotient between the value and the maximum capacity of the system and the value of the actually expected requirement to which it will be subjected; in other words, it indicates the excess of capacity that the system has over its requirements. Figures 8-10 depict the results of the simulation of the three types of matrixes. The safety values were as follows: 0.38 and 0.13 for radial at 1000 and 2900 PSI $(6894.7 \mathrm{kPa}$ and $19994.8 \mathrm{kPa}), 0.47$ and 0.16 for spiral at 1000 and 2900 PSI $(6894.7 \mathrm{kPa}$ and $19994.8 \mathrm{kPa})$, and 0.55 and 0.19 for hexagonal at 1000 and 2900 PSI $(6894.7 \mathrm{kPa}$ and $19994.8 \mathrm{kPa})$.

From these results, a flat die type-pelletizing machine was designed based on the European standard EN 14961-2. Results from FEA simulation showed that the design of the radial, spiral, and hexagonal matrices under a load of 1000 PSI and 2900 PSI $(6894.7 \mathrm{kPa}$ and $19994.8 \mathrm{kPa}$, respectively) is not affected in their mechanical structure. The maximum displacement for radial and hexagonal was $0.3946 \mathrm{~mm}$ and $0.3289 \mathrm{~mm}$ at a load of 2900 PSI $(19994.8 \mathrm{kPa})$, respectively. These demonstrate that geometry is an important factor during the design; hexagonal matrix will generate more production of pellets in a hexagonal/radial matrix ratio of $150 / 72$. It is possible to double the production with the configuration of the hexagonal 


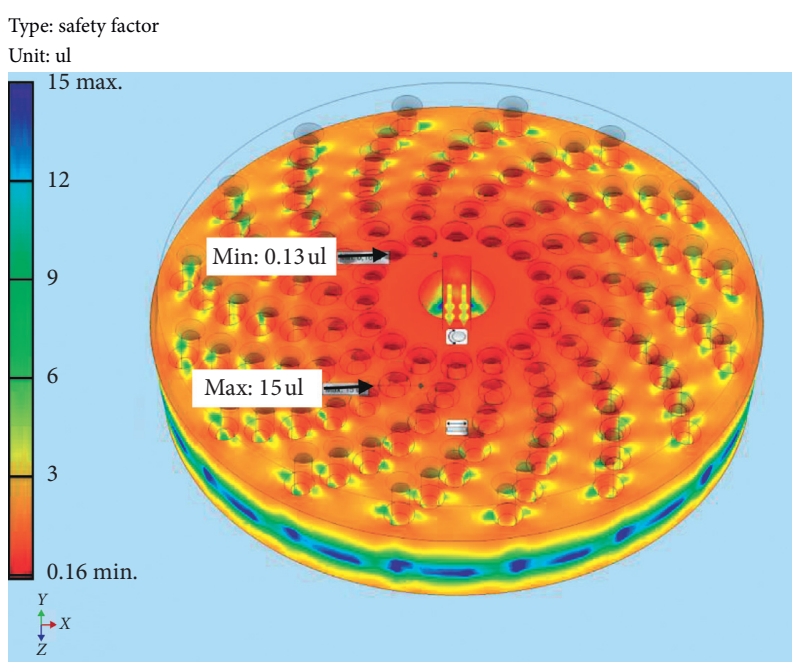

(a)

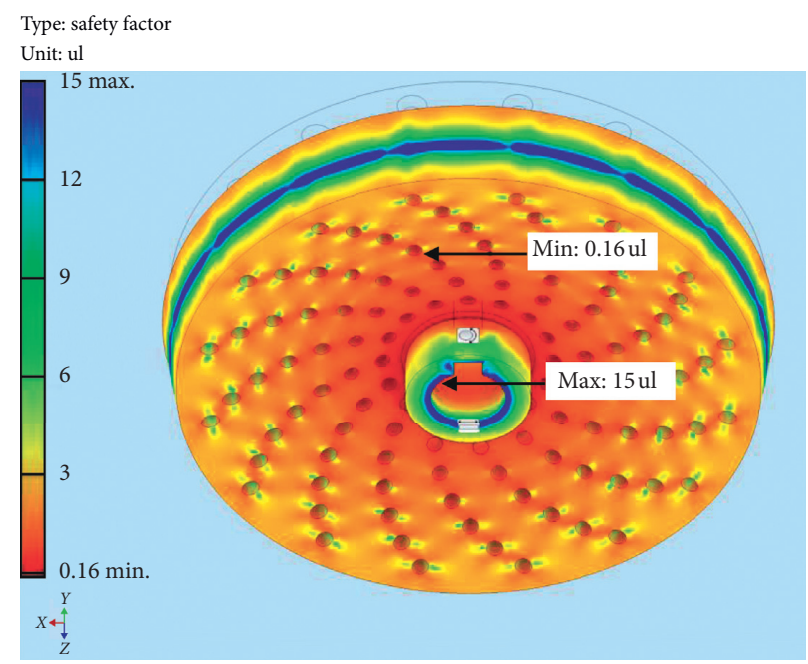

(b)

Figure 9: Safety factor from static analysis of spiral matrix at (a) 1000 PSI and (b) 2900 PSI (6894.7 kPa and $19994.8 \mathrm{kPa}$, respectively).

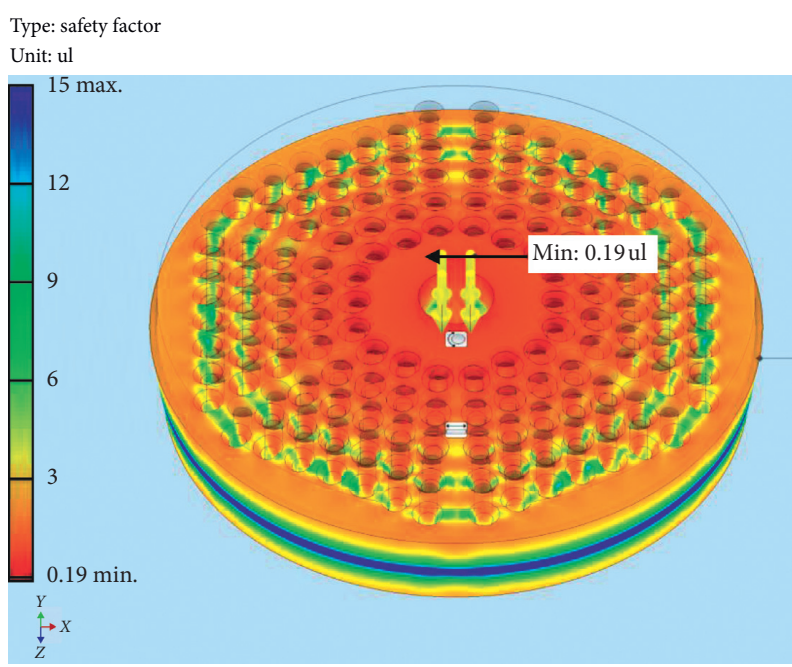

(a)

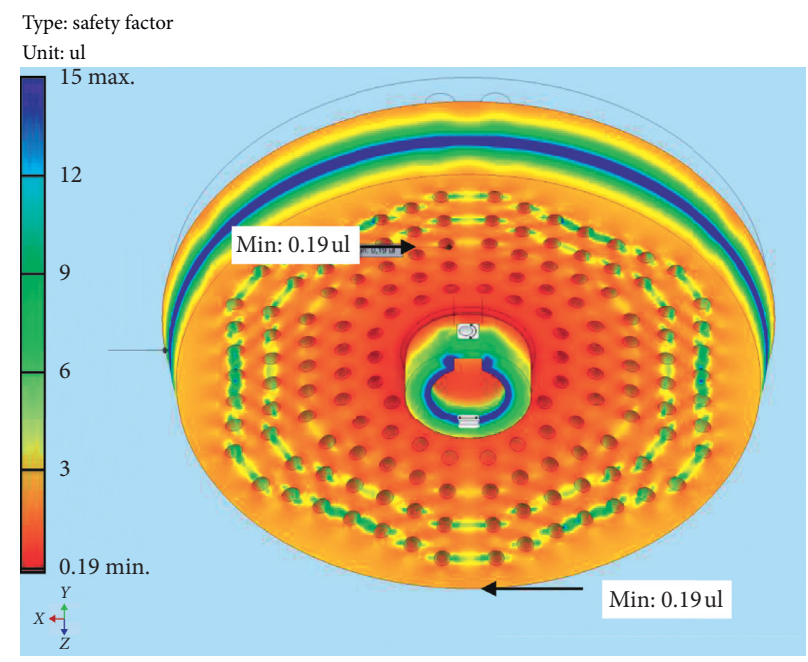

(b)

FIGURE 10: Safety factor from static analysis of hexagonal matrix at (a) 1000 PSI and (b) 2900 PSI (6894.7 kPa and $19994.8 \mathrm{kPa}$, respectively).

matrix; this configuration will not affect the structure of the machine. The pellet machine was designed in 304 stainless steel and carbon steel, a production from 300 to $1220 \mathrm{~kg} / \mathrm{h}$ for a pellet of $6 \mathrm{~mm}$ in diameter and $30 \mathrm{~mm}$ in length, respectively. The pellet production process is complex because different factors are involved: the type of biomass, humidity, compaction pressure, design and material type of the machine, particle size, sawdust temperature, and matrix speed of rotation.

To support this design, we emphasize on a physical test of compaction, where the pressure, biomass composition, and size particle play a key role. As it is mentioned by Castellano et al. [21], the composition of biomass plays a key role in the quality of pellets since it has an effect on the amount of friction within the channels matrix and determines the potential for particle agglomeration. Similar research studies the raw materials for the production of pellets: fescue, alfalfa, sorghum, triticale, miscanthus, and willow [22], whereas others study the percentage of relative humidity which is an important factor for the production of pellets [23]. It is important to mention that the biomass is not only applied in energy purposes; Souri et al. have studied the nitrogen release as factor of a plant growth after the production of pellet fertilizers as the added value from cow manure. They mention that a low compact pressure is preferred for these purposes $[6,7]$.

For the numerical simulation by FEA, the compacting pressure used in this work was of $6.89 \mathrm{MPa}$ and $20 \mathrm{MPa}$ (1000 and 2900 PSI), while for the physical test, four different pressures were considered: 0.344, 0.689, 3.447, and $6.894 \mathrm{MPa}(50,100,500$, and $1000 \mathrm{PSI})$, respectively. 
Different studies related to the theoretical compression pressure justify an interval between $188 \mathrm{MPa}$ and $295 \mathrm{MPa}$. Also, it is mentioned that the biomass, temperature, humidity, and particle size are determinant in the compacting pressure [24]. Compacting pressures of 8.65-9.5 MPa have been reported in the pellet production at the pilot scale [25].

There are different models for the design of the pellet machine [26]; however, the results of this finite-element study and the physical compaction tests showed that it is possible to manufacture pellets with this design, complying with EN 14961-2. Another important point is that the machine design is standardized in order to be manufactured quickly and economically.

\section{Conclusions}

A flat die type-pelletizing machine was designed based on the European standard EN 14961-2 (define the characteristics of the pellet) and the CENT/TS 14691 standard (European Certification for solid biofuels). This machine was designed in stainless steel 304 and carbon steel, a production of 30 to $60 \mathrm{~kg} / \mathrm{hr}$ for a pellet of $6 \mathrm{~mm}$ in diameter and $30 \mathrm{~mm}$ in length; three types of matrix were designed: radial, spiral, and hexagonal; these were compared through simulating for better pellet production. The design was validated through the finiteelement method at the three types of matrix and physical compaction tests were performed at different pressures: 50, 100,500 , and 1000 PSI $(344.7,689.4,3447.38$, and $6894.7 \mathrm{kPa})$.

The results of the simulation by finite elements show that the designs of the matrixes, radial, spiral, and hexagonal, under a load of 1000 PSI and 2900 PSI (6894.7 kPa and $19994.8 \mathrm{kPa})$, are not affected in their mechanical structure; the static analysis shows that the geometry is an important factor in the design of the matrixes and the hexagonal matrix generates more production of pellets in a ratio of $2: 1$ compared to the radial type, while physical compaction tests show the manufacture of pellets with pressures around of 1000 PSI.

The pellet production process is complex because different factors are involved such as type of biomass, humidity, compaction pressure, design and material type of the machine, particle size, sawdust temperature, and speed of rotation of the matrix between others. For this reason, this work will continue to produce different pellets with different physicochemical parameters and to analyze how those parameters affect the quality of the pellets. The design of this machine is technically standardized in order to be built quickly and economically; however, its construction is necessary to carry out the corresponding tests by taking into account all the factors that can affect the production of the pellets.

\section{Nomenclature}

$P_{\text {roller }}:$
$\mp:$
$\in x:$
$a=0.8-0.9$ and
$b=1.2-1.5:$
$A_{\text {die }}:$

Pressure of roller

Yield stress average during strain

Strain extrusion

Empirical constants at an angle between $50^{\circ}$ and $60^{\circ}$

Die surface

$Y_{\mathrm{s}}:$
$h_{\mathrm{f}}:$
$P_{\mathrm{O}}:$
$\mu:$
$h_{0}:$
$D_{\text {roller }}:$
$r_{\text {roller }}:$
$a_{\text {roller }}:$
$\rho_{\text {stainless }}:$
$n v_{\text {roller }}:$
$R:$
$Q:$

\section{Data Availability}

The data used to support the findings of this study are available from the corresponding author upon request.

\section{Conflicts of Interest}

The authors declare that there are no conflicts of interest regarding the publication of this paper.

\section{Acknowledgments}

The authors acknowledge the financial support provided by the Secretaría de Investigación y Posgrado (SIP) of Instituto Politécnico Nacional (IPN) México through the SIP 20192030, 20190040, and 20196710 Projects.

\section{Supplementary Materials}

Table S1: pellet main parameters and their corresponding values. Table S2: formula and data of parameters related to the sawdust compression in the die. Table S3: formula and data of parameters related to the roller. Table S4: formula and data of parameters related to the matrix and work surface. Table S5: formula and data related to the required power, the screw, and crown. Table S6: formula and data related to the hopper design. (Supplementary Materials)

\section{References}

[1] W. Czekała, S. Bartnikowska, J. Dach et al., “The energy value and economic efficiency of solid biofuels produced from digestate and sawdust," Energy, vol. 159, pp. 1118-1122, 2018.

[2] F. Martins, C. Felgueiras, M. Smitkova, and N. Caetano, "Analysis of fossil fuel energy consumption and environmental impacts in European countries," Energies, vol. 12, no. 6, p. 964, 2019.

[3] D. M. Nikolaevich, F. E. Evgenevna, P. O. Vadimirovna, M. A. Alievich, and O. S. Valerievich, "Study of innovative technologies in the energy industry: nontraditional and renewable energy sources," Entrepreneurship and Sustainability Issues, vol. 6, no. 4, pp. 1704-1713, 2019. 
[4] D. Hernández, H. Fernández-Puratich, R. Rebolledo-Leiva, C. Tenreiro, and D. Gabriel, "Evaluation of sustainable manufacturing of pellets combining wastes from olive oil and forestry industries," Industrial Crops and Products, vol. 134, pp. 338-346, 2019.

[5] I. M. Ríos-Badrán, I. Luzardo-Ocampo, J. F. García-Trejo, J. Santos-Cruz, and C. Gutiérrez-Antonio, "Production and characterization of fuel pellets from rice husk and wheat straw," Renewable Energy, vol. 145, pp. 500-507, 2020.

[6] M. K. Souri, M. Rashidi, and M. H. Kianmehr, "Effects of manure-based urea pellets on growth, yield, and nitrate content in coriander, garden cress, and parsley plants," Journal of Plant Nutrition, vol. 41, no. 11, pp. 1405-1413, 2018.

[7] M. K. Souri, M. Naiji, and M. H. Kianmehr, "Nitrogen release dynamics of a slow release urea pellet and its effect on growth, yield, and nutrient uptake of sweet basil (Ocimum basilicum L.)," Journal of Plant Nutrition, vol. 42, no. 6, pp. 604-614, 2019.

[8] W. Stelte, A. R. Sanadi, L. Shang, J. K. Holm, J. Ahrenfeldt, and U. B. Henriksen, "Recent developments in biomass pelletization-a review," Bioresources, vol. 7, no. 3, p. 40, 2012.

[9] M. Klemm, R. Schmersahl, C. Kirsten et al., "Upgraded "new" solid biofuels," in Energy from Organic Materials (Biomass): A Volume in the Encyclopedia of Sustainability Science and Technology, M. Kaltschmitt, Ed., pp. 451-481, Springer New York, New York, NY, USA, 2nd edition, 2019.

[10] A. I. Papadopoulos, I. Tsivintzelis, P. Linke, and P. Seferlis, Computer-Aided Molecular Design: Fundamentals, Methods, and Applications, Elsevier, Amsterdam, Netherlands, 2018.

[11] P. Pal, R. Kumar, N. Srivastava, and J. Chowdhury, "A visual basic simulation software tool for performance analysis of a membrane-based advanced water treatment plant," Environmental Science and Pollution Research, vol. 21, no. 3, pp. 1833-1849, 2014.

[12] R. Tauro, M. Serrano-Medrano, and O. Masera, "Solid biofuels in Mexico: a sustainable alternative to satisfy the increasing demand for heat and power," Clean Technologies and Environmental Policy, vol. 20, no. 7, pp. 1527-1539, 2018.

[13] H. K. Celik, H. Yilmaz, A. E. W. Rennie, R. Cinar, and M. Z. Firat, "Determination of the failure susceptibility of a flat die used in biomass pelletizing machines by means of FEA-based design exploration," Journal of Failure Analysis and Prevention, vol. 18, no. 5, pp. 1099-1110, 2018.

[14] P. M. Kurowski, Engineering Analysis with SolidWorks Simulation 2010, SDC Publications, Mission, KS, USA, 2010.

[15] S. Döring, Pellet Production, Power from Pellets: Technology and Applications, Springer, Berlin, Geramny, 2013.

[16] M. Macko and A. Mroziński, Computer Aided Design of Wood Pellet Machines, Springer International Publishing, Cham, Switzerland, 2019.

[17] Ľ. Šooš, J. Bábics, J. Beniak, P. Križan, P. Kovač, and M. Matúš, "Design and testing functional model compacting machine for produce new shape biofuels," IOP Conference Series: Materials Science and Engineering, vol. 501, Article ID 012008, 2019.

[18] M. Macko and A. Mrozinski, "Work parameters research of wood pellet machine," in Proceedings of the AIP Conference 2077, Cesme-Izmir, Turkey, May 2019.

[19] Ľ. Šooš, M. Matúš, J. Beniak, and P. Križan, “Development of the compaction machine for the production of new shapes of pressed biofuels," IOP Conference Series: Materials Science and Engineering, vol. 297, Article ID 012008, 2018.

[20] U. D. Olawale, E. A. Ademola, S. Taofeek, I. Nageri, A. Olayemi, and I. Rita, "Development and performance evaluation of A low-cost hydraulic-operated biomass briquetting machine," Journal of Engineering and Technology, vol. 3, no. 1, pp. 1-6, 2018.

[21] J. M. Castellano, M. Gómez, M. Fernández, L. S. Esteban, and J. E. Carrasco, "Study on the effects of raw materials composition and pelletization conditions on the quality and properties of pellets obtained from different woody and non woody biomasses," Fuel, vol. 139, pp. 629-636, 2015.

[22] M. Puig-Arnavat, L. Shang, Z. Sárossy, J. Ahrenfeldt, and U. B. Henriksen, "From a single pellet press to a bench scale pellet mill-pelletizing six different biomass feedstocks," Fuel Processing Technology, vol. 142, pp. 27-33, 2016.

[23] Y. Huang, M. Finell, S. Larsson et al., "Biofuel pellets made at low moisture content-influence of water in the binding mechanism of densified biomass," Biomass and Bioenergy, vol. 98, pp. 8-14, 2017.

[24] W. Stelte, J. K. Holm, A. R. Sanadi, S. Barsberg, J. Ahrenfeldt, and U. B. Henriksen, "Fuel pellets from biomass: the importance of the pelletizing pressure and its dependency on the processing conditions," Fuel, vol. 90, no. 11, pp. 3285-3290, 2011.

[25] M. Ståhl and J. Berghel, "Energy efficient pilot-scale production of wood fuel pellets made from a raw material mix including sawdust and rapeseed cake," Biomass and Bioenergy, vol. 35, no. 12, pp. 4849-4854, 2011.

[26] J. E. Arpi Trujillo and C. S. Calderón Toral, "Diseño de una máquina pelletizadora en base a la disponibilidad de residuos madereros de la ciudad de Cuenca para su aprovechamiento energético," Ingeniero Mecánico, Facultad de Ingenierías, Carrera de Ingeniería Mecánimca, Universidad Politecnica Salesiana, Cuenca, Ecuador, 2010. 